\title{
'I will keep and character that name': Dramatis Personae Lists in Early Modern Manuscript Plays
}

\begin{abstract}
W.W. Greg's claim that manuscript plays containing character lists were intended for publication (print or manuscript) and not playhouse use fails to account for all of the evidence in surviving manuscripts. Instead, as this essay demonstrates, a more significant variable in the inclusion of character lists in manuscript plays is the writer's professional or amateur status. This article argues that amateur playwrights, influenced by their experiences as readers of printed plays, were more likely than professionals to include the 'readerly' device of a dramatis personae list in their manuscript plays, even in the case of playhouse manuscripts.
\end{abstract}

In late 1632, during his long return voyage to London from Persia, East India Company clerk Walter Mountfort passed the time by writing a play that he intended to sell to a professional playing company upon his return. ${ }^{1}$ When he returned to London in the spring of 1633, Mountfort supplied his manuscript of The Launching of the Mary, or, The Seaman's Honest Wife to a troupe of actors, who in turn paid for a license from the master of the revels and then began to prepare it for performance, though no evidence confirms that the players eventually staged the play. ${ }^{2}$ Mountfort wrote his play as a dedicated playgoer, recalling the playhouses he had years earlier frequented and then left behind when he sailed to Persia. He was not a professional dramatist and no evidence suggests that he was attempting to become professional; he was, rather, one of a handful of 'amateur' dramatists who wrote their own plays and supplied them to, or imagined supplying them to, professional playing companies.

On the second page of his manuscript, Mountfort recorded a two-column list headed 'The actors', by which he meant the characters in his play. ${ }^{3}$ The manuscript of Launching presents, then, an important exception to

Matteo Pangallo (pangallo@fas.harvard.edu) is a junior fellow in the Society of Fellows at Harvard University. 
W.W. Greg's generalization - which subsequent scholars have taken largely without question - that early modern manuscript playbooks did not include character lists. Greg's theory does not give adequate attention to the important effect of amateur playwrights gaining their experience of the theatre as, primarily, consumers of plays rather than producers of them. Mountfort wrote a manuscript copy that he intended a professional bookkeeper to use in a commercial London theatre; he included in that copy a formal feature - the character list — that he assumed the bookkeeper and the actors would require in order to stage his play. What led him to make this erroneous assumption, and how it may serve as a cautionary example about evidence in plays by amateur dramatists, is the principal point upon which this article focuses. We must recognize Mountfort's status as an amateur, an outsider to the institutionalized manuscript culture of the playhouse, to best account for the character list in the Launching manuscript. That other amateur playwrights tended to include dramatis personae lists in their manuscripts, while their professional counterparts usually did not, speaks to the dichotomous life of play-texts in print, for readers, and in manuscript, for players, and the disruption of that dichotomy when an individual familiar with plays only in print crossed into the world of plays in manuscript and brought into one medium the values and expectations of the other.

In the last thirty years, scholarship on early modern dramatic manuscripts has challenged and refined many of the theories first proposed by Greg in his 1925 'Prompt Copies, Private Transcripts, and the "Playhouse Scrivener" and which also underpinned his 1931 Dramatic Documents from the Elizabethan Playhouses. Greg's ideas, however, were themselves an attempt to dismiss an even earlier speculative system of playbook taxonomy proposed in 1902 by Sidney Lee and which for nearly two decades the scholarly community never critically questioned. One of the features that Lee suggested a manuscript originating from the playhouse would always contain was a list of characters; Lee assumed that such a list would be necessary for casting and would therefore be a regular component of playbooks. ${ }^{4}$ Greg dismissed this generalization by claiming that such lists are 'uniformly absent' from extant manuscripts that bear evidence of playhouse use. 5 Such lists, Greg claimed, were purely 'literary features', only used in copies made for presentation to patrons or in transcripts of plays being prepared for print publication. ${ }^{6}$ While scholars have nuanced many of Greg's other theories, they have generally followed his claims about dramatis personae lists without question. ${ }^{7}$ 
Factors beyond playhouse or publication provenance, however, influenced the formal elements that appear in early modern play manuscripts and so a more complex, multivariable manuscript taxonomy is needed if we are to account for the nature of these peculiar documents. In the case of the appearance of a dramatis personae list in a particular manuscript play, the professional status of the playwright — that is, whether he was a regular member of the commercial theatre industry or whether he was an outsider to that industry, an 'amateur' - has more weight than the provenance of that manuscript. Distinguishing between the manuscript plays of professional and amateur dramatists thus reflects a larger condition of dramatic and textual culture in the period: the influence of print upon manuscript practices.

\section{'A Scheme of Posture': The History of the Dramatis Personae List in England}

In order to clarify what a character list is, how it developed, and why it might variously appear in both print and manuscript plays, I will first outline the history of its use and appearance in English dramatic texts. Such a consideration of the character list's history shows that in early Tudor interludes these lists tried to address the performance needs of, for the most part, amateur producers. Up until the 1570s, lists provided helpful suggestions for doubling and thus explicitly addressed the casting needs of would-be performers. Following the widespread professionalization of the theatre after the 1570 s, the purpose of the list evolved in response to the playbook-buying public's shift from a market comprised largely of potential amateur playmakers to one comprised almost exclusively of readers: that is, from a market of mostly producers to a market of mostly consumers. Subsequent lists focused much more on the relationships between fictional characters within the world of the play than on the staging of those characters in performance. Later in the seventeenth century, lists giving the names of professional actors who had taken particular roles were again linked to performance; these lists, however, speak to performances that had already occurred, rather than, like their Tudor predecessors, performances that could yet occur. Regardless of the ends at which such lists seemed aimed, however, they were a ubiquitous feature of printed plays for most of the period. As the next section demonstrates, one result of this ubiquity was that a reader of printed plays who was not familiar with backstage manuscript materials would probably view such a list as a necessary textual element for the production of a play. First, however, in 
order to appropriately situate that analysis, we must better understand the development of the character list in early modern play-texts, and, indeed, the period's concept of what the dramatic 'character' itemized in such a list really was.

The character Cicero in the anonymous Every Woman in Her Humor (published 1609) has his work cut out for him as he tries to convince Terentia to requite the love of his friend, Lentulus: the more the great orator insists that she should love Lentulus, the more she insists on loving Cicero instead, proclaiming that she will 'keepe and Character [Cicero's] name' within her heart. ${ }^{8}$ Terentia's use of 'character' refers to the act of writing as a means for preserving something indefinitely. Thomas Elyot, in 1538, had defined 'character' as 'a token, a note made with a pen', but by the end of the sixteenth century the term had come to mean more particularly the style of one's handwriting; 'character' meant 'the fashion of a letter' to Edmund Coote in 1596 and, to John Bullokar in 1616, the 'forme of a letter.'? The roots of this meaning date to the fourteenth century and associate 'character' with a distinctive mark, stamp, or engraving, which also underwrites Terentia's use of the word as a verb (a new use of the word that evidently began with Shakespeare's Hamlet in 1604). ${ }^{10}$ Over the seventeenth century, the modern meaning of 'character' as a person's identity emerged out of this earlier etymology: when the chirographic style of handwriting can be associated with one individual, that writing can then stand for that individual. In the theatre, the terms only fully slipped together in 1664, when John Dryden coined the term 'Characters' to describe the 'imaginary persons' inhabiting his play The Rival Ladies. ${ }^{11}$ These theatrical 'characters' were characters in both senses of the word: distinct marks written upon the page and representations of distinct individuals with personalities that set them apart from others. ${ }^{12}$ Long before Dryden, however, dramatists, scribes, and stationers recognized the importance of connecting the concept of the individual persona with its written expression in the play, and the character list - already familiar as a reader's aid in many early printed classical plays ${ }^{13}$ — served as the ideal space in which to make that connection. The purposes for such a guide, however, changed over time, in response to changes in how playreaders were using dramatic texts.

Use of the specific phrase 'dramatis personae' to head a character list in an English play originated with the 1602 quarto of Thomas Dekker's Satiromastix; ${ }^{14}$ most early modern play-texts head such lists with phrases such as 'Actors', 'Interlocutors', 'The Speakers', 'The Actors' Names', 'The Persons 
and Actors', 'Persons', and 'The Division of the Parts'. ${ }^{15}$ These lists appear either at the beginning or - in early texts and, in a notoriously peculiar example, the 1623 folio of Shakespeare's plays - at the end of the play and itemize the names of the characters as well as often their functions, titles, and/or relationships. The order in which names are given varies, usually taking the form of either socio-political rank or importance in the play. Lists are almost always stratified by gender, with male roles at the top and female roles at the bottom (more on the possible reason for this below). Occasionally lists group characters by alliance, family, or domain - for example, the characters in the list for Gigantomachia are bracketed into the groupings of 'Gods', 'Giants', and 'Hills'. ${ }^{16}$ Modest visual innovations in the dramatis personae list occur in the period, usually in the use of brackets, lines, and columns aimed at helping readers understand how characters are connected. The modern convention of listing characters in the order of their appearance - a convenience for readers trying to follow who is who in the play - appeared in printed classical drama, possibly derived from manuscript copying practices (a list arranged sequentially by speech order would be easiest for a scribe to compile as he made his copy of the play), but only occasionally imported into the vernacular in a few texts recounting private entertainments, such as Thomas Hughes et al's Inns of Court play The Misfortunes of Arthur (1587), Thomas Middleton's Masque of Heroes (1619), and Middleton and William Rowley's masque The World Tossed at Tennis (1620). Lists in order of appearance may have also been meant to help readers recreate the theatrical experience of the performance.

A more peculiar use of a list to suggest the blocking of a performance occurs in the posthumous quarto of William Strode's 1636 Oxford allegory The Floating Island (1655). The quarto includes a traditional dramatis personae list in its prefatory material, with 'Persons' organized by social rank and importance in the play and accompanied by brief descriptive tags explaining their roles. ${ }^{17}$ As with most such explicating lists, Strode's is anticipatory and anti-dramatic, providing readers prior knowledge about the relationships between characters that an audience in the theatre can work out only as the play unfolds. Because of such lists, play-readers approach the fiction of the play seeking confirmation of what they already know about these relationships, and so the play, when read, takes on the effect of an encounter with a static and fixed event (particularly if the list reveals the identity of disguised characters or characters whose true identity is not uncovered until the final act); lacking such lists, playgoers must wait and discover any information 
about relationships and characters in real time, lending the play, when seen, a dynamic and potentially evanescent effect. Such descriptive lists, then, stand in for the bodies of the actors as memorializing tokens, or reminders, of the 'imaginary people' of the play. Strode took this concept of the list as a surrogate for the physical presence of the actors one step further, however, with his chart titled 'A Scheme of Posture', which serves as a spatial dramatis personae list emphasizing the rank relationships of the characters in the final scene, as well as, perhaps, their placement on the stage.

Strode's 'scheme of posture' appears at the end of his play, a position that later printed dramatic texts generally avoided (for reasons explained below) even though it was the place where the earliest lists in English manuscript drama first appeared. Character lists in English drama originated in the mid-fifteenth century with inventories of character names in the colophon of manuscript plays, such as the 'hec sunt nomina ludentium' [these are the names of the players] on the final leaf of The Castle of Perseverance (ca 1440), the listing of 'The namys and numbere of the players' on the final leaf of the Play of the Sacrament (ca 1530) ('IX may play yt at ease'), and the interlocutores list on Robert Wilmot's post-1566 Inns of Court play Gismond of Salerene. ${ }^{18}$ Providing readers with aids for identifying relationships between characters was a practice imported from the continent, where printers had been experimenting with such formal devices in classical drama. For example, Strasbourg printer Johann Reinhard Grüninger's 1496 collection of Terence's comedies includes six woodcuts of scenes from the plays with labels naming the characters, which was a fairly typical tool for identifying dramatic characters; less typical, however, is his woodcut for Adelphi, which uses a system of lines linking characters and locations in order to visually demonstrate the relationships between the personae, as well as between personae and settings.

English scribes and printers were generally less experimental than continental printers in how they identified characters in plays, for the most part limiting themselves to listing characters' names on the final leaf or page. Some exceptions exist, however; Hycke Scorner (1515?), for example, perhaps the first printed English playbook to provide a guide to dramatis personae, uses six labeled character woodcuts on the verso of its title-page. Such illustrated lists persisted even later into the period, particularly in the plays of Middleton; ${ }^{19}$ in later examples, however, such illustrations became less comprehensive and more selective in presenting only certain characters from the play. That is, rather than aids for the reader in navigating the action of the play, they became sites of imaginative engagement that could help 
play-readers adopt the visual habits of the playhouse spectator, associating a physical body with the textual character and situating that body within a particular, usually fictional, setting. More practically, they also became marketing devices for selling unbound play quartos as they sat on booksellers' tables. ${ }^{20}$ Over the sixteenth century, a few printers retained the older manuscript practice of listing characters at the end of a play; for example, the 'names of the players' in John Rastell's 1530 edition of John Skelton's moral interlude Magnifycence (printed by Peter Treveris) and Rastell's 1530 edition of Henry Medwall's Interlude of Nature appear on the final page after the text of the play. ${ }^{21}$ In these instances, however, the title-pages present the texts as records of events from the past (Magnyfycence was 'duysed and made by mayster Skelton / poet laureate late deceasyd' and Nature was 'cópylyd by mayster Henry Medwall'). A more peculiar example is Derick van der Straten's 1548 octavo of John Bale's morality interlude The Three Laws of Nature, Moses, and Christ, which includes a list of 'interlocutores' on the verso of the titlepage, but at the end also explains that 'Into fyue personages maye the partes of thys Comedy be duyded', suggesting van der Straten's assumption that some of his customers might want to stage it themselves. ${ }^{22}$ Again, however, he presents the text as a record of a past event, with the colophon explaining that the interlude was 'Compyled by Iohan Bale'. ${ }^{23}$ With the exception of van der Straten's edition of The Three Laws, the position of the character list at the end of these texts, and their emphasis upon the text's status as documentation of a performance that has already occurred, suggest that they were meant for buyers interested simply in reading the texts privately (the identity of characters would have been, for most readers, irrelevant in the decision whether or not to purchase the book).

Notwithstanding these few peculiar examples, however, we can deduce the larger market for printed scripts from the fact that, in most interludes and entertainments, lists of characters appear at the very start of the document, on the title-page. ${ }^{24}$ In this place, the list could serve as advertising to buyers interested in how to cast the play for their own performances; most title-page dramatis personae lists in early printed interludes explicitly delineate how parts could be doubled or tripled to accommodate casts of various sizes. ${ }^{25}$ Even the convention of dividing the list by gender may have developed to assist buyers in quickly determining how many adult actors and how many boy actors they would need to cast the play. These casting-oriented lists address the amateur producer and their rhetorical openness signals the collaborative nature of theatrical production that empowers the producer to do 
whatever he might wish, or need, to do to make the script a performance. The earliest title-page list of 'namys of the pleyers', for example, in John Rastell's Nature of the Four Elements (1520?), concludes with the deferential note, 'Also yf ye lyst ye may brynge in a dysgysynge'. ${ }^{26}$ The title-page list in John Heywood's The Play of the Weather (1533) implicitly acknowledges that different producers will encounter different circumstances in casting, noting that the part of the boy should be taken by 'the lest [that is, smallest] that can play'. ${ }^{27}$

From the 1530s into the 1560s, many more stationers placed character lists on the title-page, as in Rastell's 1534 edition of Heywood's Inns of Court interlude A Play of Love, van der Straten's 1547 quartos of John Bale's antiCatholic interludes God's Promises and The Temptation of Our Lord, and John King's 1560 quarto of the anonymous Nice Wanton. The first title-page list to suggest that the roles might be doubled appears in the 1557(?228 Wealth and Health; the first title-page list to indicate how to double the parts is the 1560 Impatient Poverty, which apportions the roles such that 'Foure men may well and easelye playe thys Interlude'. ${ }^{29}$ This new title-page convention of printed plays influenced some scribes and authors in their manuscripts; for example, the scribe who copied Francis Merbury's university play The Marriage Between Wit and Wisdom (1578?) divided both the roles and physical space on the first leaf, specifying 'The deuision of the partes for six to playe this interlude' ${ }^{30}$

Occasionally stationers placed lists in the preliminary material but not on the title-page, as with the 'names of the Speakers' on the second page of William Griffith's 1565 octavo of Thomas Norton and Thomas Sackville's Ferrex and Porrex (also known as Gorboduc). ${ }^{31}$ Most character lists in early plays, however, appear on the title-page, again, likely a result of that page's function as the principal means for marketing the book: stationers, because they sold plays unbound, evidently assumed that a list of how to double the roles for performance would appeal to most potential customers as they browsed the bookstalls. Because stationers usually left pages uncut in the pre-sold book, the placement of marketing devices, such as the casting list, on the inside of the text block would have been counterproductive. ${ }^{32}$ Who, then, were the customers to whom these lists should have appealed? Gary Taylor suggests that these lists indicate that, 'before 1580, booksellers expected a significant proportion of the purchasers of printed plays to be interested, not simply in reading, but actually in performing the plays they bought'. ${ }^{33}$ More specifically, Richard Dutton notes that the character list 
on the title-page of Thomas Preston's Cambises (1569) fits the thirty-eight parts to a company of eight actors, which was 'a typically-sized professional troupe of that period', and suggests that the printer was encouraging professional troupes to adopt the play into their repertoires. ${ }^{34}$ David Bevington also draws upon casting information in early lists in order to reconstruct the possible composition and doubling practices of professional playing companies in the Tudor period. ${ }^{35}$ No doubt some buyers of early printed plays were members of professional troupes, but the intended readers for these interludes also included individuals who lacked a professional understanding of how plays were made into performances. For one thing, most plays with character lists that instruct on doubling are aimed at companies of four or six players, which, as Dutton himself observes, is much smaller than the typical professional troupe of the time. Furthermore, certain lists include explanations of the theatrical laws governing the practice of doubling, as in John Wyer's 1550 (?) quarto of R. Wever's Lusty Juventus: 'Foure may play it easely, takyng such partes as they thinke best: so that any one tak of those partes that be not in place at once. ${ }^{36}$ For professionals, a list describing how to double parts is convenient, but an explanation of theatrical exigency would be unnecessary; for amateurs unfamiliar with staging plays and thus potentially unaware of problems that they may encounter, such advance instructions could prove helpful in avoiding unforeseen difficulties. Even more to the point, the character list in Richard Bradock's 1581 edition of Nathaniell Woodes's 1572 The Conflict of Conscience divides the parts for six actors who are 'disposed, either to shew this Comedie in priuate houses, or otherwise', a formulation that suggests the author's (or stationer's) understanding that most buyers will be using the script for amateur performance. ${ }^{37}$ In addition, though many itinerant professional troupes appeared in the Tudor period, their limited number and wide geographic dispersal beyond the primary book-selling area of London would not have made them, on their own, a sufficiently sized market to justify stationers' commitment of financial investment in the publication of plays. Most professional troupes, after all, would have staged their plays using manuscript playbooks, plots, and parts, and not bulk purchases of printed quartos. Stationers must have assumed that a larger prospective pool of customers wanted to purchase and stage, or perhaps simply read aloud, these plays. ${ }^{38}$ Every buyer who was not a professional player was a potential amateur player, and the potential amateur players were most likely the primary targets of the early London play publishers. 
Perhaps the most telling piece of evidence that the majority of buyers or, at least, intended buyers - of these early printed interludes were amateur players is that the professionalization of the theatre in the 1570 s corresponds with the rapid disappearance of the role-apportioned character list. As the ranks of amateur players dwindled after the 1570 s, stationers' inclinations to market printed plays as scripts for amateur performance also waned: excluding closet drama, between 1520 and 1569, approximately 85\% of printed plays with character lists place that list on the title-page, as compared to just under 20\% between 1570 and 1609, and most of those post-1570 lists appear on reprints of older interludes (figure 1). The last printed play with a title-page dramatis personae list as a guide to doubling is the 1581 Conflict of Conscience, with its explicit indication of amateur performance. ${ }^{39}$ As soon as the industry established its fixed London theatres, title-page lists dividing characters for performance largely vanished. Between 1600 and 1609, no title-page lists were printed at all. Indications of apportioning of parts for a particularly-sized company disappear almost entirely, with the exception of Henry Rocket's 1607 quarto of the anonymous play (often attributed to Thomas Heywood) The Fair Maid of the Exchange, in which a note before the list assures buyers that 'Eleauen may easily acte this Comedie. ${ }^{40}$

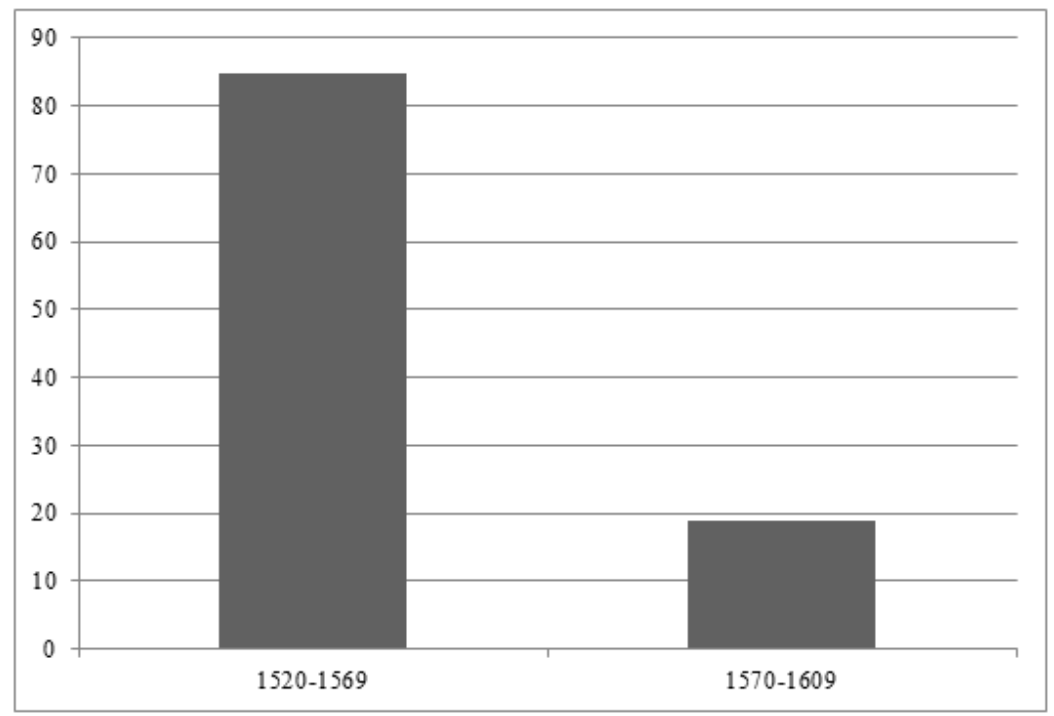

Fig. 1. Percentage of printed playbooks with dramatis personae lists that place that list on the title-page 
The transition from character lists as performance texts to reading texts further solidified as the professional theatre came into ascendance. The last decades of the sixteenth century and first of the seventeenth saw printed plays with dramatis personae lists that presented detailed information on the function and relationships of characters rather than how those characters could be doubled or tripled for performance. Later in the seventeenth century, printed plays - such as the 1629 quartos of Massinger's Roman Actor and James Shirley's The Wedding — provided lists that included professional actors' names, a marketing feature that would appeal to readers who had seen the performance, or at least knew who those actors were, and which would help the reader envision the play as it had been staged (by professionals) in the past rather than how it could be staged (by amateurs) in the future. Later scribes who prepared presentation manuscripts sometimes adopted this practice from the print tradition, as in the British Library's copy of Arthur Wilson's comedy The Swisser (ca 1630). Emphasizing the idea of the play-text as a record of an event that has occurred as opposed to a blueprint for an event yet to come contributed to the professionalization of the theatre industry. Some lists went even further in conveying their status as memorials of past professional performances. While nearly every other play that gives the actors' names places those names after the names of the characters, the 1629 quarto of Lodowick Carlell's The Deserving Favorite lists the actors before the roles they played, literally giving precedence to the past performance of the play over the current fiction of the play. Slightly different, but with similar effects, the 1623 quarto of John Webster's The Duchess of Malfi documents the play's performance history in its character list by itemizing two different casts of actors - one from the play's December 1614 premiere and the other from its revival sometime between 1619 and 1623. After 1642 and the closure of the public theatres, some lists - such as those in the 1652 edition of John Fletcher's The Wild Goose Chase and the 1655 edition of Robert Davenport's King John and Matilda - included short, editorial asides on the quality of actors' performances, as if helping readers to recall (or imagine) performances once seen on stages now no longer in existence. These nostalgic post-1642 lists seem implicitly to caution their readers not to attempt a performance of their own, for it would only fall short of the unattainable ideal set by the professional players of the past.

All of these changes suggest that most stationers and scribes recognized that the majority of consumers of written plays, both in print and manuscript, had transformed from a market comprised largely of potential 
play-makers to a market comprised largely of private, silent play-readers. Because potential buyers no longer principally purchased the book for use in their own performances, placement of character lists shifted from the titlepage into the preliminaries, where readers could consult them as reference tools in proximity to, often directly facing, the start of the first act. ${ }^{41}$ The history of the development of the character list, from a document aimed at creating a performance to a document aimed at imagining either a fiction or a past performance, is therefore the history of the transformation of the play-reading public itself, from one of potential amateur producers to one of almost entirely consumers.

Random Cloud charges modern editors of Shakespeare's plays with the intervention of 'the dramatis-personae list [that] has insinuated itself between the title-page and the opening of Act 1, Scene 1', but the historical precedent of this evolution of the form and purpose of printed dramatic texts in the period justifies such placement. ${ }^{42}$ Before 1589 , stationers printed most character lists on A1r of their plays; after 1589, most lists were printed on A1v. So complete was this change in placement and function that scholars have come generally and unquestioningly to assume that any list of characters in a play is, as Jeffrey Masten claims, an 'indication of its constitution as a readerly text; ${ }^{43}$ in the same vein, Taylor summarily concludes that '[character] lists are designed for readers, not actors' and Cloud suggests that such lists are 'helpful to a reader', but, by implication, do not speak towards the play's theatrical context as a performance document. ${ }^{44}$ This perspective — attuned to the later professional drama but not adequately taking into account English drama's amateur roots - overlooks the origin of the dramatis personae list in early English dramatic texts as a tool expressly meant for making the written script into a performed play. In the period character lists were long viewed as bearing a relationship to performance, even though modern scholars have generally assumed that such lists were only for readers. This assumption of character lists as distinctly reading-oriented devices impelled Greg's view that their presence in manuscript plays always signals that the playwrights did not intend those manuscripts for performance use but were, instead, literary copies being prepared either for presentation or print publication. He most plainly articulates this theory in describing the title-page and dramatis personae list added by a later hand to the authorial playhouse manuscript of The Two Noble Ladies (1619-23); remarking on the leaf, Greg concludes that there is "hardly ... a doubt that it was added with a view to publication. ${ }^{45}$ He then extends this claim into a general rule, suggesting that 
'only when [a manuscript] was prepared for printing was a list of personae added'; 46 Greg's rule, however, ignores the question of personae lists included by the author or scribe in a manuscript used, potentially used, or intended to be used for performance. Subsequent scholars who remark on character lists in manuscript plays have usually taken Greg's pronouncement as final and assume that a character list in a manuscript play signals either a 'literary' copy of a play or a copy prepared in order to enter print. This theory, however, does not account for all of the extant evidence.

\section{'A printed play or two': The Influence of Print on Manuscript Play Practices}

In order to test Greg's claim that theatrical manuscripts generally lack dramatis personae lists, I cross-tabulated the use or lack of use of such lists in a sample of fifty-nine play manuscripts against variables such as authorial or playhouse provenance, manuscript type, and the professional or nonprofessional status of the author. ${ }^{47}$ Not surprisingly, Greg is largely accurate: manuscripts with evidence of playhouse use (bookkeepers' revisions, censorship by the master of the revels, or both) almost always lack dramatis personae lists. Greg's characterization of dramatis personae lists as 'uniformly absent' from playhouse manuscripts, however, glosses over some important exceptions to his rule. As noted above, at least one theatrical playbook from the professional theatre does have such a list (The Launching of the Mary), as does one playhouse scribal copy of a playbook: John Clavell's 1630 King's Men comedy The Soddered Citizen. The playhouse manuscript of The Welsh Embassador also contains a dramatis personae list, though it seems that the copyist added it after writing out the rest of the document; ${ }^{48}$ it may, then, have been a scribal interpolation rather than an authorial list in the scribe's copytext, though its presence again contradicts the generalization that playhouse manuscripts 'uniformly' lack such lists. Similarly, despite Greg's claim otherwise, many fair copies made for readers lack a list, as with the six manuscript copies of Middleton's A Game at Chess: one of these is an authorial transcript (the Trinity College copy), three are scribal transcripts (the Huntington and the two Folger copies), and two are scribal transcripts made by playhouse scribe Ralph Crane for presentation (the Bodleian and the British Library copies), but none contains a dramatis personae list. Although they clearly prepared their transcripts for readers, neither Crane nor the anonymous scribes nor Middleton himself evidently thought it appropriate or necessary 
to add a list of characters. This absence of a list where Greg's theory suggests a list should appear — that is, in a transcript prepared expressly for a reader - recurs with other manuscripts, such as the scribal presentation copy of Fletcher's The Woman's Prize and the presentation copy of the university drama Heteroclitanomalonon. As the sample suggests, the basis for the flaw in the binary division of play manuscripts is the idea that those that include a list could not emerge from the playhouse and those that lack a list could not be intended for readers. A variable other than readerly/playhouse provenance alone must factor into the presence or absence of this textual feature.

One explanation may be in the relationship between the play's author and the professional stage: of the 33 manuscripts in the sample lacking dramatis personae lists, professional dramatists (regular, paid writers for the commercial players) wrote $79 \%$ (26), amateurs $9 \%$ (3), and unidentified authors $12 \%$ (4); of the 26 possessing dramatis personae lists, professional dramatists wrote $8 \%$ (2) and amateur dramatists $92 \%$ (24) (see figure 2). The manuscript of a play written by a dramatist not familiar with the usual working practices of the professional stage is more likely to include a dramatis personae list than the manuscript of a play written by a dramatist familiar with those practices, even if the nonprofessional's play appears in a playhouse manuscript and the professional's play in a 'literary' copy. ${ }^{49}$ Mountfort's Launching of the Mary and the Trinity copy of Middleton's Game at Chess are clear examples of

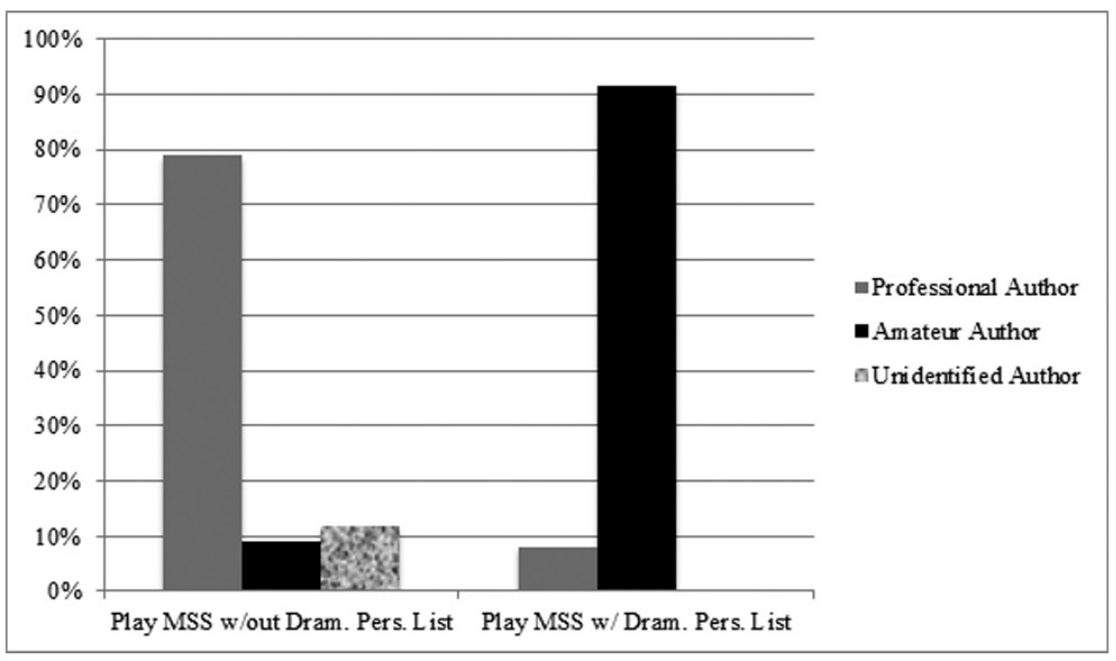

Fig. 2. Use of dramatis personae lists in play manuscripts sampled 
this distinction: both are authorial manuscripts of plays for the professional stage, but one is an amateur's playbook (which, according to Greg, should not include a list) and the other a professional's presentation copy (which, according to Greg, should include a list). ${ }^{50}$ In this instance, however, we must reverse Greg's theory: the amateur's playbook contains a character list; the professional's presentation copy does not.

As the sample shows, both authorial and scribal manuscripts might contain dramatis personae lists, but no authorial fair copy by a professional dramatist contains a list. Indeed, the only two professional plays in the sample that do have character lists original to the manuscript are the scribal copies of the anonymous Dick of Devonshire (which, Greg suggests, may have never been intended for the stage ${ }^{51}$ and Crane's presentation copy of Middleton's The Witch. The possibility that a professional scribe, such as Crane, added a dramatis personae list to a presentation copy without consulting the author is possible. Scribal emendations to transcripts were common, particularly if the scribe believed that such changes might result in 'a presentable text, able to perform its perceived social function. ${ }^{52}$ In a culture that, after the 1570s, viewed dramatis personae lists as aids for readers (see above), a professional scribe could have reasonably added a list if his exemplar lacked one and his fair copy was being prepared for a reader. At the same time, however, a scribe would probably retain such a list if it appeared in his exemplar. Scribal transcripts that contain lists — of which the majority are of plays by amateur dramatists - may reflect what the author had already included in his foul papers, or, possibly, what an intermediary scribe - professional or amateur - had added to the text in a transcript made earlier than the extant copy. It is highly unlikely that a scribe would omit a list if it were included in his exemplar, whether or not that exemplar was a transcript (scribal or authorial) or foul papers; a scribal transcript that lacks a list thus likely derives from a prior manuscript that also lacked a list. Without the manuscript that served as the scribe's copy, we cannot determine, based only on knowing if the extant transcript is scribal or authorial, whether or not the exemplar foul papers did indeed contain a list. When the variable of the author's professional or nonprofessional status is factored in, however, odds become easier to weigh: manuscripts of plays by amateur dramatists are more likely to contain a dramatis personae list than manuscripts of plays by professional dramatists, no matter whether the type of manuscript is authorial copy, scribal copy, or foul papers. Indeed, the very fact that amateurs' play manuscripts with lists appear across all of these categories points to an 
underlying factor to explain the inclusion of those lists, something that holds true whether the manuscript was made by author or scribe. This sample suggests that the provenance (playhouse, author, or scribe) or purpose (playbook or reading copy) of a manuscript is not sufficient to account for the inclusion or omission of a character list. A more precise correlation can be established only when we introduce the question of the author's professional status or degree of proximity to the working practices of the professional playhouse. A writer outside of that domain, without recourse to the documents professional playwrights customarily used — including, most importantly, the 'author's plot' which usually recorded a cast list - would find the most convenient example for his play in printed play-texts. Print, not manuscript, was the medium in which most members of the public encountered the text of professional plays, even though manuscript, not print, was the medium from which most actors produced professional plays.

Not only were general readers unlikely to encounter a play in manuscript - especially a playhouse manuscript - but even players outside of the professionalized industry almost always turned to printed playbooks for acting texts of professionals' plays. Middleton satirizes a troupe of amateur 'country comedians' in Hengist, King of Kent (published in 1661 as The Mayor of Queenborough) and notes that the avocational actors 'abuse simple people with a printed play or two, which they bought at Canterbury for six pence..$^{53}$ Actual amateurs who staged professionals' plays corroborate Middleton's fictional version. Sir Edward Dering, for example, one of the best known theatre aficionados of his day, adapted for private performance the printed texts of plays he had seen on the London public stages, including Shakespeare's Henry IV plays, for performance in his home at Surrenden by household members. ${ }^{54}$ For Henry $I V$, Dering oversaw a scribe's creation of a new manuscript, but his copy-text was in print, for he combined and revised from the versions of the plays appearing in the 1623 Shakespeare folio. Dering's surviving folio reveals that he also marked up for performance other plays, including Macbeth, Measure for Measure, and The Winter's Tale. ${ }^{55}$ In other instances, Dering purchased multiple copies of individual quartos for use as scripts, including Fletcher and Massinger's The Spanish Curate (1620-30) and a play that was either Beaumont's The Woman Hater (1607) or the anonymous Swetnam, the Woman Hater (1620). Amateurs who generated their own original material for performance did use manuscripts for their performances, but even in these instances, amateurs writing for 
amateur players - like amateurs who wrote for professional players - were likely to include a character list.

Professionals' plays in manuscript certainly circulated beyond the playhouse, but these were almost always presentation copies; ${ }^{56}$ rarely would someone outside of the playhouse - with the exception of the master of the revels - encounter a theatrical manuscript of a professional play. T.H. Howard-Hill has shown that the usual type of commercial manuscript publication - what Harold Love refers to as 'entrepreneurial publication' — was neither economically viable nor logistically feasible for the authors of dramatic manuscripts. ${ }^{57}$ Most playgoers, play-readers, and amateur playmakers who encountered dramatic texts from the professional theatres encountered those texts in print. This fact may explain why certain features common to printed plays, such as the dramatis personae list, appear so often in the manuscripts of amateurs' plays. First-time playwrights, turning to the familiar and widely available printed drama for a model to follow in the physical layout of their texts, would naturally incorporate these lists in their manuscripts. The result was a document resembling formal elements derived from printed plays, but not necessarily intended for print publication. Rather, in plays by amateurs, the influence of print often came from the opposite direction: these lists emerged from, and were not always directed toward, the conventions and expectations of print.

Book historians have well established the depths to which early modern manuscript culture continued to operate within and affect a culture coming to be dominated by print, often identifying evidence of chirographic elements infiltrating printed documents or of printers mimicking the devices of scribes (as with those early printed interludes that, following the scribal practice of putting the character list in the colophon, printed character lists at the end of the book). Interpreting the inclusion of dramatis personae lists in manuscript plays as evidence of the manuscript's preparation for publication assumes that this evolution was the only possible relationship between print and manuscript drama; that is, as plays moved towards print publication for readers, they were made to conform with normative readerly expectations in that medium, including the addition of dramatis personae lists. While true in certain instances, the conduit of influence could also reverse: practices associated with plays prepared in print for readers could influence play manuscripts prepared for performance, particularly if the writer was only familiar with play-texts through the conventions of print culture. As Henry Woudhuysen argues, 'the emergence of an apparently print-dominated 
culture did not result in a movement one way only. As movable type transformed manuscript into print, so print ... could be transformed back into manuscript ${ }^{58}$ Printed plays, for example, particularly classical drama of the sixteenth century, were the source of the act-division formula eventually adopted in English manuscript plays. ${ }^{59}$ Classical plays exercised a particular influence over the printing of plays: every Latin play printed in early modern England included a character list and so it may have been a recognizably classical form that certain stationers, scribes, and authors, eager to associate their dramatic texts with that prestigious tradition, sought to emulate. ${ }^{60}$ As the examples of act divisions and of dramatis personae lists in manuscript plays both indicate, interactions between print and manuscript drama were dialogic, with one often serving as an exemplar to the other. ${ }^{61}$ This dialogue derives from the larger cultural and material relationship between the two media in the period. David McKitterick suggests that it is more realistic to speak not of one [tradition] superseding the other, but of the two working together', a position held also by D.F. McKenzie, who insists that, materially and conceptually, manuscript and print engage with each other in complementary, not competitive, ways. ${ }^{62}$ Love and Woudhuysen, too, demonstrate that authors, stationers, and readers in the period viewed manuscript 'without any sense of [it] being inferior [to print] or incomplete'. ${ }^{63}$ The infiltration of printed plays' dramatis personae lists into manuscript plays further corroborates the degree to which the different forms of media exchanged influence in a circular, rather than strictly linear, fashion.

The early modern commercial playhouse was a persistent microcosm of manuscript culture within a cultural macrocosm increasingly dominated by print. Amateur playwrights, whose experiences with dramatic texts were confined almost entirely to reading printed plays, were, for the most part, immigrants to the playhouse's manuscript culture, largely unfamiliar with the uses, forms, and idiosyncrasies of its many documents. ${ }^{64}$ This distinctly 'outsider' perspective is easy to overlook if we take too literally the period's most famous (fictional) amateur playmakers: the mechanicals in Shakespeare's A Midsummer Night's Dream (1595-6), whose scroll with 'the names of the actors' includes also the roles that they are to play (1.2.8). ${ }^{65}$ Though both other characters in the play and modern critics ridicule their dramatics as stereotypically 'amateurish', the mechanicals nonetheless come to their production armed with a peculiarly professional battery of manuscript materials, including 'the scroll' of the actors and roles, parts or 'sides', 'a bill of properties', and a separately written prologue $(1.2 .4,12,54,78$, 
83, and 3.1.18-20). Rather than evidence of actual amateur practices, the mechanicals' use of professional manuscript materials may be an instance of Shakespeare, an industry insider, perhaps unknowingly resorting to what he assumes to be the 'proper' way of making a performance. The professional dramatist has therefore imported into an amateur context the working practices of the professional theatre.

In much the same way, amateur dramatists transported across the permeable border between consumer and producer the concepts, assumptions, and perceptions of their own native culture. Lacking access to the usual manuscript practices of the industry, they borrowed (perhaps inadvertently) from what their exposure to plays in print taught them to be - they assumed conventional and even necessary. Love suggests that writers would 'not only write differently but also adopt different conceptions of the function of writing as they turned from one medium to the other. ${ }^{6} 6$ For most amateur dramatists, however, concepts of 'the function of writing' evidently shifted little from the needs of play-readers to what they thought to be the needs of playmakers.

The frequent use of dramatis personae lists in amateurs' manuscript plays stands as evidence of the heterogeneity of textual media in early modern England and in theatrical culture especially. More specifically, it serves as a caution that generalized theories about early modern dramatic manuscripts must take wider account of authors' relative relationships to the professionalized playhouse and its manuscript culture. Recently, scholars such as Grace Ioppolo, Paul Werstine, and others have identified some of the problems caused by the New Bibliography's assumed division of manuscripts along simplistic and tidy categories of provenance. ${ }^{67}$ The dialogic relationship between print and manuscript serves as another complicating determinant in the period's systems of play-text production, as did the fact that some dramatists who wrote for the theatre industry does so with little knowledge of its manuscript conventions. Scholarship will err if it assumes that all authors who wrote for the professional playhouses shared the same proximity to the working procedures of those playhouses. Not every playwright was professional; we should not, then, read every manuscript play, even if written for the professional stage, as if they were. 


\section{Notes}

Research for this article was supported by the Bibliographical Society of the UK, the University of Massachusetts Amherst deans of the College of Humanities and Fine Arts and of the graduate school, and the Malone Society. This article — in various forms - has benefited from feedback from many individuals, but particularly Arthur Kinney, Adam Zucker, Harley Erdman, and especially Grace Ioppolo, whose patience and forthrightness with me in this and other projects has spared me many an otherwise embarrassing error, oversight, or misstatement. I wish, also, to thank Helen Ostovich, Erin Kelly, and the anonymous readers at Early Theatre for helping to improve the article immeasurably.

1 On Mountfort and his play, see Frederick Boas, Shakespeare and the Universities (Oxford, 1923), 167-82 and Matteo Pangallo, "Seldome Seene": Observations from Editing The Launching of the Mary', Pete Orford et al (eds), 'Divining Thoughts': Future Directions in Shakespeare Studies (Cambridge, 2007), 2-16. In one of his lengthy stage directions, Mountfort indicates his expectation of a performance, explaining that the play's complex staging 'shall be shewed [to the actors] before the daye of action'; Walter Mountfort, The Launching of the Mary, or, The Seaman's Honest Wife, ed. John Henry Walter (Oxford, 1933), 11 2674-5. Because the troupe paid the master of the revels to license the play, the play was prepared for a professional public performance; G.E. Bentley, The Jacobean and Caroline Stage (Oxford, rpt 1966-8), 4.924.

2 Gary Taylor claims that the title page references 'the play's successful performances', but no such reference exists; Gary Taylor, 'The Order of Persons', Gary Taylor and John Lavagnino (eds), Thomas Middleton and Early Modern Textual Culture: A Companion to the Collected Works (Oxford, 2007), 52 n24.

3 W.W. Greg suggests that the list was a later addition in his Dramatic Documents from the Elizabethan Playhouses (Oxford, 1931), 300. Other scholars have followed Greg; see, for example, Taylor, 'Order of the Persons', 52 n24. The Launching list, however, appears in the same ink and on the same paper stock as the rest of the manuscript, and even bears the same type of weathering from Mountfort's sea voyage as the rest of the manuscript; Mountfort therefore added the list at the same time he wrote the play.

4 Sidney Lee (ed.), Shakespeare's Comedies, Histories, \& Tragedies, being a Reproduction in Facsimile of the First Folio Edition 1623 from the Chatsworth Copy (Oxford, 1902), 20. Although Greg disproved this claim, Lee's logic occasionally remains attractive to scholars. For example, David Bradley assumes that the 'partial cast-list' in the 
quarto of Believe As You List proves that it was 'printed from prompt copy'; David Bradley, From Text to Performance in the Elizabethan Theatre (Cambridge, 2009), 88.

5 Greg, Dramatic Documents, 189. To account for how casting occurred, Greg assumed the existence of a type of playhouse document that he referred to as the 'Cast'. Although he admits that 'No example ... is known to survive', Greg supposed that such a document would have been made for 'every play produced' and may have become the copy-text for the dramatis personae lists in the preliminaries of printed plays; Greg, Dramatic Documents, 73 and 73 n1; see also Bradley, From Text to Performance, 84. Greg was not the first to make this suggestion: in 1923, Crompton Rhodes proposed that such a list could serve as 'a remembrancer for casting, or as a catalogue to a bundle of written parts' for a bookkeeper responsible for making order out of a library of parts, plots, and playbooks; Crompton Rhodes, Shakespeare's First Folio (Oxford, 1923), 118. Such a document was not necessary: extant playhouse plots usually contain, in their stage directions, the names of actors and characters; T.J. King, Shakespearean Staging, 1599-1642 (Cambridge MA, 1971), 40-3; see also Bradley, From Text to Performance, 83. Greg's idea still resurfaces, however; see, for example, Paul Werstine, Early Modern Playhouse Manuscripts and the Editing of Shakespeare (Cambridge, 2013), 9. doi: http://dx.doi.org/10.1017/ CBO9781139103978.

6 W.W. Greg, The Shakespeare First Folio (Oxford, 1955), 121; see also 355 n3.

7 See, for example, Taylor, 'Order of the Persons', 52 and 61-3.

8 Anonymous, Everie Woman in her Humor (London, 1609), C4r.

9 Ian Lancashire (ed.), Lexicons of Early Modern English (Toronto, 2012).

10 'character n.' and 'character v.', Oxford English Dictionary (Oxford, 2012).

11 John Dryden, The Rival Ladies (London, 1664), A2r.

12 On relationships between identity and naming, see Anne Barton, The Names of Comedy (Oxford, 1990).

13 Howard-Hill observes that classical plays in translation commonly use dramatis personae lists as aids for readers; T.H. Howard-Hill, 'The Evolution of the Form of Plays in English During the Renaissance', Renaissance Quarterly 43 (1990), 134. doi: http://dx.doi.org/10.2307/2861794.

14 Thomas Dekker, Satiromastix (London, 1602), A2r. The OED erroneously claims that 'dramatis personae' was first used in 1730.

15 On distinctions between these terms, see Bernard Beckerman, 'The Persons Personated: Character Lists in English Renaissance Play Texts', Koshi Nakanori and Yasuo Tamaizumi (eds), Poetry and Drama in the English Renaissance: In Honour of Professor Jiro Ozu (Tokyo, 1980), 61-9; see also Taylor, 'Order of the Persons', 63-5. 
16 Suzanne Gossett and Thomas Berger (eds), Collections Volume XIV: Jacobean Academic Plays (Oxford, 1988), 101.

17 William Strode, The Floating Island (London, 1655), A4v.

18 The Castle of Perseverance colophon is Folger V.a.354 f 191r; The Play of the Sacrament colophon is Trinity (Dublin) Ms F.4.20 f 356r; the colophon of Gismond of Salerne is BL Hargrave Ms 205 f 22r. On these colophon lists, see Howard-Hill, 'Evolution of the Form of Plays', 129.

19 Taylor, 'Order of the Persons', 55.

20 Marjorie Plant, The English Book Trade: An Economic History of the Making and Sale of Books (London, 1965), 248.

21 John Skelton, Magnifycence (London, 1530), H2r; Henry Medwall, Interlude of Nature (London, 1530), i4r.

22 John Bale, The Three Laws of Nature, Moses, and Christ (London, 1548), G1v.

23 Ibid, G4r.

24 Howard-Hill, 'Evolution of the Form of Plays', 116.

25 Bradley, From Text to Performance, 17.

26 John Rastell, Nature of the Four Elements (London, 1520[?]), A1r.

27 John Heywood, Play of the Weather (London, 1533), A1r.

28 The Database of Early English Plays dates Wealth and Health as '[1565?]', but John Walley entered it in the Stationers' Register in August 1557; W.W. Greg, A Bibliography of the English Printed Drama to the Restoration (Oxford, 1939), 1.1.

29 Anonymous, Impatient Poverty (London, 1560), A1r. As noted above, however, the first play to include a doubling cast list was van der Straten's 1548 edition of Bale's The Three Laws, in which the list appears on Glv.

30 Francis Merbury, The Marriage Between Wit and Wisdom, ed. T.N.S. Lennam (Oxford, 1971), 11 9-10. Merbury may have copied his manuscript from a no-longer extant printed version of the play that included the divided list (ix-x).

31 Thomas Norton and Thomas Sackville, Ferrex and Porrex (London, 1565), A2r.

32 On plays sold unbound, see Peter W.M. Blayney, 'The Publication of Playbooks', John D. Cox and David Scott Kastan (eds), A New History of Early English Drama (New York, 1997), 414.

33 Taylor, 'Order of the Persons', 56.

34 Richard Dutton, Mastering the Revels: The Regulation and Censorship of English Renaissance Drama (Iowa City, 1991), 39.

35 David Bevington, From Mankind to Marlowe (Cambridge MA, 1962), 68-85.

36 R. Wever, Lusty Juventus (London, 1550[?]), A1r.

37 Nathaniell Woodes, The Conflict of Conscience (London, 1581), A1r. 
38 Doubling would be of less concern for a reading than for a performance because in a reading one voice could take multiple roles in a single scene.

39 The last title-page list (not divided into parts) appeared on the 1594 quarto of Marlowe's Dido, Queen of Carthage and the last division of the parts (not on the title page) appeared in the 1598 quarto of Mucedorus.

40 Anonymous, The Fair Maid of the Exchange (London, 1607), A2r.

41 The publishers of the 1623 Shakespeare folio included dramatis personae lists for seven plays, placing them - like the colophon lists in earlier interludes - at the end of each play. While some scholars argue that these lists were made by King's Men scribe Ralph Crane (see, for example, Margreta de Grazia and Peter Stallybrass, 'The Materiality of the Shakespearean Text', Shakespeare Quarterly 44 (1993), 267 n46. doi: http://dx.doi.org/10.2307/2871419.), E.A.J. Honigmann sees them as printed versions of Greg's 'Cast' document, made by the author for both writing and playhouse use; E.A.J. Honigmann, The Stability of Shakespeare's Texts (Lincoln, 1965), 44-6.

42 Random Cloud, “The very names of the Persons”: Editing and the Invention of Dramatick Character', David Scott Kastan and Peter Stallybrass (eds), Staging the Renaissance: Reinterpretations of Elizabethan and Jacobean Drama (New York, 1991), 95.

43 Jeffrey Masten, Textual Intercourse: Collaboration, Authorship, and Sexualities in Renaissance Drama (Cambridge, 1997), 117, emphasis added.

44 Taylor, 'Order of the Persons', 52 (see also 54); Cloud, 'very names of the Persons', 95.

45 Greg, Dramatic Documents, 194. On the status of The Two Noble Ladies as an authorial copy, see Rebecca G. Rhoads (ed.), The Two Noble Ladies (Oxford, 1930), vi; on the manuscript's use in the playhouse, see viii.

46 Greg, Dramatic Documents, 195.

47 See the Appendix for descriptions of the manuscripts in the sample.

48 Greg, Dramatic Documents, 195.

49 This trend (not generalization) applies to every manuscript. Within the sample there are instances that defy the trend. Ralph Crane's presentation copy of The Witch, for example, is a professional's play with a dramatis personae list; however, Crane's contemporaneous presentation copy of Demetrius and Enanthe does not.

50 On the relationship between the various texts of Game at Chess, see T.H. HowardHill (ed.), A Game at Chess (Manchester, 1993), 2-10.

51 Greg, Dramatic Documents, 330. I count the anonymous Dick of Devonshire as a professional's play because scholars have generally attributed it to either Robert Davenport or Thomas Heywood (or, less plausibly, James Shirley). 
52 Harold Love, The Culture and Commerce of Texts: Scribal Publication in SeventeenthCentury England (Amherst, 1998), 121. doi: http://dx.doi.org/10.1093/acprof:oso/ 9780198112198.001 .0001$.

53 Thomas Middleton, The Mayor of Queenborough (London, 1661), I3r.

54 George W. Williams and G.B. Evans (eds), King Henry IV as Revised by Sir Edward Dering (Charlottesville, 1974); see also Laetitia Yeandle, 'The Dating of Sir Edward Dering's Copy of “The History of King Henry the Fourth”, Shakespeare Quarterly 37 (1986): 224-6. doi: http://dx.doi.org/10.2307/2869961. On Dering as a dedicated playgoer, see Martin Butler, Theatre and Crisis, 1632-1642 (Cambridge, 1984), 104 and 124-9.

55 T.N.S. Lennam, 'Sir Edward Dering's Collection of Playbooks, 1619-1624', Shakespeare Quarterly 16 (1965), 145-53. doi: http://dx.doi.org/10.2307/2868258.

56 On the circulation of plays in manuscript beyond the playhouse, see Love, Culture and Commerce, 65-70; Butler, Theatre and Crisis, 105-6; and H.R. Woudhuysen, Sir Philip Sidney and the Circulation of Manuscripts, 1558-1640 (Oxford, 1996), 134-45. doi: http://dx.doi.org/10.1093/acprof:oso/9780198129660.001.0001.

57 Love, Culture and Commerce, 73-9; see also 126-34 and Woudhuysen, Sir Philip Sidney, 45-52; also see T.H. Howard-Hill, "Nor Stage, Nor Stationers Stall Can Showe”: The Circulation of Plays in Manuscript in the Early Seventeenth Century', Book History 2 (1999), 28-41. doi: http://dx.doi.org/10.1353/bh.1999.0004.

58 Woudhuysen, Sir Philip Sidney, 25.

59 William Long, 'John a Kent and John a Cumber: An Elizabethan Playbook and Its Implications', W.R. Elton and William Long (eds), Shakespeare and Dramatic Tradition: Essays in Honor of S. F. Johnson (Newark, 1989), 132.

60 Taylor, 'Order of the Persons', 60.

61 'Printing, and the user of the printed book, both depended on and influenced manuscripts long after the invention of printing with movable type'; David McKitterick, Print, Manuscript and the Search for Order, 1450-1830 (Cambridge, 2003), 47; see also 33-8 and 127-9; Love, Culture and Commerce, 295-6; and Walter Ong, Orality and Literacy: The Technologizing of the Word (New York, 1997), 125. doi: http:// dx.doi.org/10.4324/9780203328064.

62 McKitterick, Print, Manuscript, 21; D.F. McKenzie, 'Speech - Manuscript Print', Peter McDonald and Michael Suarez (eds), Making Meaning: 'Printers of the Mind' and Other Essays (Amherst, 2002), 238.

63 Love, Culture and Commerce, 35; Woudhuysen, Sir Philip Sidney, 20-5.

64 Certain amateurs did have the opportunity to learn about professional playing companies' manuscript practices. Amateur dramatist William Percy may have purchased playhouse manuscripts to use as models for his own writing for the 
professional stage; William Renwick (ed.), John of Bordeaux (Oxford, 1936), v-vi. Some aristocratic amateurs had personal interactions with playing companies, such as William Cavendish, earl of Newcastle, who turned to the King's Men's regular dramatist, James Shirley, for assistance writing The Country Captain (1639-40) and The Variety (1642); G.E. Bentley, The Profession of Dramatist in Shakespeare's Time, 1590-1642 (Princeton, 1986), 227, and N.W. Bawcutt (ed.), The Control and Censorship of Caroline Drama (Oxford, 1996), 209. doi: http://dx.doi.org/10.1093/ actrade/9780198122463.book.1. Such privileged amateurs, however, were in the minority. Most amateurs writing for the professional stage were dedicated playgoers but lacked the advantage of a close familiarity with the industry's regular operating practices.

65 William Shakespeare, A Midsummer Night's Dream, ed. R.A. Foakes, (Cambridge, 1984).

66 Love, Culture and Commerce, 145.

67 Grace Ioppolo, Dramatists and their Manuscripts in the Age of Shakespeare, Jonson, Middleton and Heywood (New York, 2006), especially 7-8; Werstine, Early Modern Playhouse Manuscripts, especially 4.

68 See also Greg 1931, 293-300 and C.J. Sisson (ed.), Malone Society, 1928.

69 See also Greg 1931, 321-4 and W.W. Greg (ed.), Malone Society, 1951.

70 See also Greg 1931, 369.

71 See also Greg 1931, 261-4 and J.H. Walter (ed.), Malone Society, 1938.

72 See also Greg 1931, 362-3 and Anthony Johnson (ed.), Malone Society, 1999.

73 See also Greg 1931, 364-5.

74 See also M. McL. Cook and F.P. Wilson (eds), Malone Society, 1951.

75 See also Greg 1931, 329-32 and J.G. and M.R. McManawey (eds), Malone Society, 1955.

76 See also Greg 1931, 256-61 and E. Boswell (ed.), Malone Society, 1928.

77 See also Greg 1931, 334-7.

78 See also Greg 1931, 318-21 and H.D. Janzen (ed.), Malone Society, 1978.

79 The Faithful Friends contains a dramatis personae list, but the editor, G.M. Pinciss, and Greg (1931, 194-5) concur that an eighteenth-century owner added it and so the manuscript is counted as lacking a list; John Fletcher, The Faithful Friends, G.M. Pinciss (ed.), (Oxford, 1975), x-xi. Pinciss suggests that the list 'reproduce[s] an original list' that had been part of the copy-text, but there is no evidence to support this conjecture.

80 See also Greg, 1931, 324-9 and G.M. Pinciss and G.R. Proudfoot (eds), Malone Society, 1975. 
81 See also Greg, 1931, 337-9 and S.B. Younghughes and H. Jenkins (eds), Malone Society, 1959.

82 See also Greg, 1931, 251-6 and W.P. Frijlinck (ed.), Malone Society, 1929.

83 See also Greg, 1931, 357-8.

84 Ibid, $1931,357$.

85 See also T.H. Howard-Hill (ed.), Malone Society, 1990.

86 Ibid.

87 See also Greg, 1931, 361-2.

88 See also W.L. Renwick (ed.), Malone Society, 1936.

89 See also Greg, 1931, 305-8 and A. Brown (ed.), Malone Society, 1959.

90 See also Greg, 1931, 300-5 and J.H. Walter (ed.), Malone Society, 193[2].

91 See also D.F. Rowan (ed.), Malone Society, 1987.

92 See also Greg, 1931, 342-4.

93 Ibid, 314-8.

94 See also Greg, 1931, 311-4 and K.J. Palmer (ed.), Malone Society, 1955.

95 See also Greg, 1931, 352-5 and H.D. Janzen (ed.), Malone Society, 1989.

96 See also Greg, 1931, 363-4.

97 See also Greg, 1931, 264-8 and W.W. Greg (ed.), Malone Society, 1908.

98 See also Greg, 1931, 268-74 and T.H. Howard-Hill (ed.), Malone Society, 1980.

99 See also W.W. Greg (ed.), Malone Society, 1911, rev. 1961 by H. Jenkins and 1990 by J. Pitcher.

100 See also J.H.P. Pafford and W.W. Greg (eds), Malone Society, 1936.

101 See also Greg, 1931, 361.

102 Ibid, 356.

103 See also R.A. Foakes and J.C. Gibson (eds), Malone Society, 1960.

104 The list in The Two Noble Ladies was added after the manuscript had been copied out and by a different hand (Greg 1931, 194); it is therefore counted as lacking a list. 105 See also Greg, 1931, 274-9 and R.G. Rhoads (ed.), Malone Society, 1930.

106 See also J.W. Lever and G.R. Proudfoot (eds), Malone Society, 1976.

107 See also H. Littledale and W.W. Greg (eds), Malone Society, 1920.

108 See also W.W. Greg and F.P. Wilson (eds), Malone Society, 1950.

109 See also Greg, 1931, 344-6.

110 See also Greg, 1931, 308-11 and J.M. Nosworthy and G.R. Proudfoot (eds), Malone Society, 1980. 


\section{Appendix: Manuscript Plays Sample}

The data in this article derives from the following sample of early modern manuscript plays. The sample was generated through random selection (manuscripts missing any pages where a list might appear were omitted from the study), though that selection was cultivated slightly in order to favour manuscripts on which some scholarship or for which a scholarly edition was available to supply perspective on matters such as dating, provenance, performance auspices, and authorship. Each entry includes the title and holding information for the copy, the name of the author(s) when available, an indication of whether or not the author was a professional or an amateur, whether the manuscript includes a dramatis personae list (lists added by later hands are not counted), the manuscript's nature and provenance, including type and date, and the play type and performance auspices (when these are in dispute or not apparent from the manuscript, the provenance favoured by a majority of scholars who have commented on the manuscript has been preferred). Each entry concludes with the source consulted; for most manuscripts this was either the manuscript itself or either Greg, a Malone Society edition, or, whenever possible, both. Citations to additional sources on the manuscript appear in the endnotes.

Aglaura (BL Royal 18 C.xxv)

Author: John Suckling (amateur)

Includes dramatis personae list

Manuscript type: scribal presentation copy (1637-8)

Play type: professional (King's Men)

Source: Greg 1931, 332-3

The Amazon (BL Additional 88926)

Author: Edward Herbert (amateur)

Includes dramatis personae list

Manuscript type: foul papers (1630-42?)

Play type: amateur (household?)

Source: British Library manuscript

The Tragedy of Antipo (Bodleian Eng. poet.5)

Author: Francis Verney (amateur)

Includes dramatis personae list

Manuscript type: scribal copy, likely for

presentation (1622)

Play type: amateur (academic)
Source: Bodleian manuscript

Believe As You List (вL Egerton 2828)

Author: Philip Massinger (professional)

Lacks dramatis personae list

Manuscript type: authorial transcript, likely

for performance (1631)

Play type: professional (King's Men)

Source: British Library manuscript ${ }^{68}$

Bonduca (BL Additional 36758)

Author: John Fletcher (professional)

Lacks dramatis personae list

Manuscript type: presentation copy pre-

pared by Edward Knight (1625-35)

Play type: professional (King's Men)

Source: British Library manuscript ${ }^{69}$

Boot and Spur (Folger J.a.1)

Author: unknown (amateur)

Includes dramatis personae list

Manuscript type: scribal transcript 


\section{(1613-5)}

Play type: amateur (academic)

Source: S. Gossett and T.L. Berger (eds), Malone Society Collections XIV, 1988

Candia Restaurata (BL Additional 34221)

Author: Mildmay Fane (amateur)

Includes dramatis personae list

Manuscript type: scribal transcript (1640)

Play type: private (household)

Source: British Library manuscript ${ }^{70}$

The Captive Lady (Yale Osborn ms)

Author: James Mabbe? (amateur)

Contains dramatis personae list

Manuscript type: scribal transcript, possibly with authorial corrections (1618-42?)

Play type: unknown

Source: A.R. Braunmuller (ed.), Malone

Society, 1982

The Captives (BL Egerton 1994)

Author: Thomas Heywood (professional)

Lacks dramatis personae list

Manuscript type: foul papers (1624)

Play type: professional (Lady Elizabeth's

Men)

Source: British Library manuscript (see also Greg 1931, 284-8 and A. Brown [ed.], Malone Society, 1953)

Charlemagne (вL Egerton 1994)

Author: unknown (probably amateur)

Lacks dramatis personae list

Manuscript type: authorial transcript

(1603-4?)

Play type: professional (company unknown)

Source: British Library manuscript ${ }^{71}$

The Country Captain (вL Harley 7650)

Author: William Cavendish (amateur)

Lacks dramatis personae manuscript

Manuscript type: scribal transcript with

authorial corrections (1639-41)

Play type: professional (King's Men)

Source: British Library manuscript ${ }^{72}$

The Court Secret (Worcester College

Oxford Ms)

Author: James Shirley (professional)
Lacks dramatis personae list

Manuscript type: scribal transcript with

authorial corrections (1642?)

Play type: professional (King's Men,

unacted)

Source: Greg 1931, 346-52

The Cyprian Conqueror (вL Sloane 3709)

Author: unknown (amateur)

Includes dramatis personae list

Manuscript type: scribal transcript with authorial corrections (1640?)

Play type: unknown

Source: British Library manuscript 73

Demetrius and Enanthe (Harlech Collection, Brogyntyn 42)

Author: John Fletcher (professional)

Lacks dramatis personae list

Manuscript type: scribal transcript for presentation prepared by Ralph Crane (1619?)

Play type: professional (King's Men)

Source: Greg 1931, 359-6074

Dick of Devonshire (BL Egerton 1994)

Author: Robert Davenport? (professional)

Includes dramatis personae list

Manuscript type: scribal transcript by play-

house scribe (1626?)

Play type: professional (company unknown)

Source: British Library manuscript ${ }^{75}$

Edmond Ironside (BL Egerton 1994)

Author: unknown (professional)

Lacks dramatis personae list

Manuscript type: scribal transcript for

performance (1590-1600)

Play type: professional (company unknown)

Source: British Library manuscript ${ }^{76}$

The Elder Brother (BL Egerton 1994)

Author: unknown (unknown type)

Lacks dramatis personae list

Manuscript type: scribal transcript

(1630-40)

Play type: unknown

Source: British Library manuscript ${ }^{77}$

The Emperor's Favorite (Arbury Hall A414)

Author: John Newdigate? (amateur) 
Includes dramatis personae list

Manuscript type: foul papers (1627-32)

Play type: unknown

Source: Siobhan Keenan (ed.), Malone

Society, 2010

The Escapes of Jupiter (BL Egerton 1994)

Author: Thomas Heywood (professional)

Lacks dramatis personae list

Manuscript type: foul papers (1620-41)

Play type: professional (possibly the Red

Bull company)

Source: British Library manuscript ${ }^{78}$

The Faithful Friends (Victoria \& Albert

Dyce 10)

Author: unknown (professional)

Lacks dramatis personae list ${ }^{79}$

Manuscript type: scribal transcript possibly

for performance (1620-30?)

Play type: professional (company unknown)

Source: Victoria and Albert Library

manuscript ${ }^{80}$

The Fatal Marriage (BL Egerton 1994)

Author: unknown (unknown type)

Lacks dramatis personae list

Manuscript type: scribal transcript (1620?)

Play type: unknown

Source: British Library manuscript ${ }^{81}$

The First Part of King Richard the Second

(Thomas of Woodstock) (BL Egerton 1994)

Author: unknown (professional)

Lacks dramatis personae list

Manuscript type: scribal playbook (1590-3; revised 1603-22)

Play type: professional (unknown)

Source: British Library manuscript ${ }^{82}$

A Game at Chess (Bodleian Malone 25)

Author: Thomas Middleton (professional)

Lacks dramatis personae list

Manuscript type: scribal transcript for

presentation prepared by Ralph Crane with authorial corrections (1624-5)

Play type: professional (King's Men)

Source: Greg 1931, 357
A Game at Chess (BL Lansdowne 690)

Author: Thomas Middleton (professional)

Lacks dramatis personae list

Manuscript type: scribal transcript for presentation prepared by Ralph Crane (1624-5) Play type: professional (King's Men) Source: British Library manuscript ${ }^{83}$

A Game at Chess (Folger V.a.231)

Author: Thomas Middleton (professional)

Lacks dramatis personae list

Manuscript type: scribal transcript prepared by Ralph Crane (1624-5)

Play type: professional (King's Men)

Source: Folger Library manuscript

A Game at Chess (Folger V.a.342)

Author: Thomas Middleton (professional)

Lacks dramatis personae list

Manuscript type: scribal transcript with authorial corrections (1624-5)

Play type: professional (King's Men)

Source: Folger Library manuscript ${ }^{84}$

A Game at Chess (Huntington EL 34.B.17)

Author: Thomas Middleton (professional)

Lacks dramatis personae list

Manuscript type: scribal transcript with

authorial corrections (1624-5)

Play type: professional (King's Men)

Source: Greg 1931, 356-785

A Game at Chess (Trinity College Cam-

bridge 0.2 .66 )

Author: Thomas Middleton (professional)

Lacks dramatis personae list

Manuscript type: authorial transcript

(1624-5)

Play type: professional (King's Men)

Source: Greg 1931, $356^{86}$

The Honest Man's Fortune (Victoria \&

Albert Dyce 9)

Author: unknown (professional)

Lacks dramatis personae list

Manuscript type: playbook prepared by

Edward Knight (1613; revised 1625)

Play type: professional (King's Men)

Source: Victoria and Albert Library manu-

script (see also Greg 1931, 288-93) 
The Humorous Magistrate (Arbury Hall Ms A.414)

Author: John Newdigate? (amateur)

Includes dramatis personae list

Manuscript type: scribal transcript with

authorial corrections (1637-40)

Play type: amateur

Source: M.J. Kidnie (ed.), Malone Society, 2012

The Humorous Magistrate (University of

Calgary Osborne MsC 132.27)

Author: John Newdigate? (amateur)

Includes dramatis personae list

Manuscript type: authorial transcript

(1637-40)

Play type: amateur

Source: Jacqueline Jenkins and Mary Polito (eds), Malone Society, 2012

Hymen's Triumph (Edinburgh De.3.69)

Author: Samuel Daniel (amateur)

Includes dramatis personae list

Manuscript type: scribal transcript for

presentation (1613)

Play type: private performance?

Source: J. Pitcher (ed.), Malone Society, 1994

The Inconstant Lady (Bodleian Rawlinson poet.9)

Author: Arthur Wilson (amateur)

Includes dramatis personae list

Manuscript type: authorial transcript for presentation (1632?)

Play type: professional (King's Men)

Source: Bodleian Library manuscript ${ }^{87}$

John a Kent and John a Cumber (Huntington HM 500)

Author: Anthony Munday (professional)

Lacks dramatis personae list

Manuscript type: authorial transcript

(1590-9?)

Play type: professional (Admiral's Men?)

Source: Greg 1931, 239-43 and M. St C.

Byrne (ed.), Malone Society, 1923

John of Bordeaux (Alnwick Castle 507)

Author: Henry Chettle? (professional)
Lacks dramatis personae list

Manuscript type: playbook (1590-4)

Play type: professional (Strange's Men?)

Source: Greg 1931, 355-688

July and Julian (Folger 448.16)

Author: unknown (amateur)

Lacks dramatis personae list

Manuscript type: scribal transcript

(1559-71)

Play type: amateur (school)

Source: G.E. Dawson (ed.), Malone Society, 1955

The Lady Mother (BL Egerton 1994)

Author: Henry Glapthorne (professional)

Lacks dramatis personae list

Manuscript type: playbook (1633-5)

Play type: professional (King's Revels?)

Source: British Library manuscript ${ }^{89}$

The Launching of the Mary (BL Egerton 1994)

Author: Walter Mountfort (amateur)

Includes dramatis personae list

Manuscript type: foul papers used as

playbook, with authorial revisions (1632;

revised 1633)

Play type: professional (second Prince

Charles's Men?)

Source: British Library manuscript ${ }^{90}$

The Lost Lady (Folger J.b.4)

Author: William Berkeley (amateur)

Includes dramatis personae list

Manuscript type: scribal transcript for pres-

entation with authorial corrections (1637)

Play type: professional (King's Men)

Source: Folger Library manuscript ${ }^{91}$

Love's Changelings' Change (BL Egerton 1994)

Author: unknown (amateur?)

Includes dramatis personae list

Manuscript type: authorial transcript

(1630-40)

Play type: unknown

Source: British Library manuscript ${ }^{92}$

Nero (BL Egerton 1994) 
Author: unknown

Lacks dramatis personae list

Manuscript type: scribal transcript (1624?)

Play type: unknown (closet?)

Source: British Library manuscript ${ }^{93}$

The Poor Man's Comfort (BL Egerton 1994)

Author: Robert Daborne (professional)

Lacks dramatis personae list

Manuscript type: scribal transcript

(1615-17)

Play type: professional (Palsgrave's Men?)

Source: British Library manuscript ${ }^{94}$

The Queen of Corsica (BL Lansdowne 807)

Author: Francis Jaques (amateur)

Includes dramatis personae list

Manuscript type: authorial transcript

Play type: unknown

Source: British Library manuscript ${ }^{95}$

The Royal Slave (BL Additional 4616)

Author: William Cartwright (amateur)

Includes dramatis personae list

Manuscript type: scribal transcript for presentation (1636?)

Play type: amateur (Oxford University)

Source: British Library manuscript ${ }^{96}$

The Second Maiden's Tragedy (BL Lans-

downe 807)

Author: Thomas Middleton? (professional)

Lacks dramatis personae list

Manuscript type: playbook with authorial revisions (1611)

Play type: professional (King's Men)

Source: British Library manuscript ${ }^{97}$

Sir John van Olden Barnavelt (BL Additional 18653)

Author: John Fletcher and Philip Massinger (professional)

Lacks dramatis personae list

Manuscript type: playbook (1619)

Play type: professional (King's Men)

Source: British Library manuscript ${ }^{98}$

Sir Thomas More (BL Harley 7368)

Author: Anthony Munday, Thomas
Heywood?, Henry Chettle, William Shakespeare?, and Thomas Dekker (professional) Lacks dramatis personae list Manuscript type: foul papers used as playbook with authorial revisions (1593?) Play type: professional (Strange's Men?) Source: Greg 1931, 243-5199

The Soddered Citizen (Wiltshire Record Office 865/502/2)

Author: John Clavell (amateur) Includes dramatis personae list Manuscript type: scribal transcript used as playbook (1631-3)

Play type: professional (King's Men)

Source: Wiltshire Record Office manuscript ${ }^{100}$

The Swisser (BL Additional 36759)

Author: Arthur Wilson (amateur) Includes dramatis personae list Manuscript type: authorial transcript for presentation (1631?)

Play type: professional (King's Men)

Source: British Library manuscript ${ }^{101}$

Tancred and Ghismonda (BL Additional 34312)

Author: unknown (amateur?) Includes dramatis personae list Manuscript type: scribal transcript (1600?) Play type: unknown (closet?) Source: British Library manuscript ${ }^{102}$

The Telltale (Dulwich $\mathrm{xx}$ )

Author: unknown

Lacks dramatis personae list

Manuscript type: scribal transcript (1600-5?)

Play type: unknown

Source: Greg 1931, 339-41103

The Two Noble Ladies (вL Egerton 1994)

Author: unknown

Lacks dramatis personae list ${ }^{104}$

Manuscript type: authorial transcript for performance (1622-3)

Play type: professional (Children of the Revels?)

Source: British Library manuscript ${ }^{105}$ 


\section{iI8 Matteo Pangallo}

The Wasp (Alnwick Castle 507)

Author: unknown (professional)

Lacks dramatis personae list

Manuscript type: foul papers prepared for performance (1636-40)

Play type: professional (King's Revels)

Source: Greg 1931, $360^{106}$

The Welsh Embassador (Cardiff Public

Library Ms)

Author: unknown

Includes dramatis personae list

Manuscript type: authorial transcript, pos-

sibly for performance (1623)

Play type: unknown

Source: Greg 1931, 279-82 107

The Witch (Bodleian Malone 12)

Author: Thomas Middleton (professional)

Includes dramatis personae list

Manuscript type: scribal transcript for pres-

entation prepared by Ralph Crane (1620-7)

Play type: professional (King's Men)

Source: Greg 1931, 358-9 $9^{108}$

The Wizard (BL Additional 10306)

Author: Simon Baylie (amateur)

Includes dramatis personae list

Manuscript type: scribal transcript with

authorial corrections (1620-40?)

Source: British Library manuscript ${ }^{109}$
The Woman's Prize (Folger J.b.3)

Author: John Fletcher (professional)

Lacks dramatis personae list

Manuscript type: scribal transcript for

presentation (1607-11)

Play type: professional (King's Men)

Source: Meg Powers Livingston (ed.), Malone Society, 2008

Timon (Victoria \& Albert Dyce 52)

Author: unknown (amateur)

Includes dramatis personae list

Manuscript type: scribal transcript, possibly

for performance (1602-3)

Play type: amateur (Inns of Court)

Source: Victoria and Albert Library

manuscript ${ }^{110}$

Untitled play (Essex Record Office D/DW Z5)

Author: John Tatham (amateur)

Includes dramatis personae list

Manuscript type: scribal transcript for

presentation, fragmentary (1641-2)

Play type: unknown (private?)

Source: J.L. Murphy (ed.), Malone Society

Collections IX, 1971 